\title{
Associations between enterotoxin gene cluster types egc1, egc2 and egc3, agr types, enterotoxin and enterotoxin-like gene profiles, and molecular typing characteristics of human nasal carriage and animal isolates of Staphylococcus aureus
}

\author{
Mark M. Collery, Davida S. Smyth,† John J. G. Tumilty, Jane M. Twohig \\ and Cyril J. Smyth
}

Correspondence

Cyril J. Smyth

csmyth@tcd.ie

Received 20 July 2008

Accepted 11 September 2008

\author{
Department of Microbiology, Moyne Institute of Preventive Medicine, Trinity College Dublin, \\ University of Dublin, Dublin 2, Republic of Ireland
}

Twenty genes encoding enterotoxin and enterotoxin-like proteins have been described in Staphylococcus aureus strains. Five of these occur commonly in the enterotoxin gene cluster (egc: selo, selm, sei, seln and seg). In the sei-seln intergenic region, two pseudogenes, $\psi$ ent1 and $\psi$ ent2, can be present or an additional gene designated selu or a variant seluv. Whilst frequencies of loci bearing pseudogenes (egc1) or the selu gene (egc2) have been reported, the distinction between selu-bearing and seluv-bearing (egc3) loci has rarely been made. A PCRRFLP procedure involving cleavage of the sei-seln intergenic region by restriction endonuclease Bbvl or Tsel was developed that allowed differentiation of selu ${ }^{+}$and seluv ${ }^{+}$loci. In addition, PCR primers were designed to yield a $203 \mathrm{bp}$ amplimer for sequencing of a selu or selu intragenic region, which encompassed ten signature nucleotide differences. A total of $43 \mathrm{egc}^{+}$human nasal isolates and $53 \mathrm{egc}^{+}$bovine, ovine, caprine, leporine and gallinaceous isolates were egc typed and agr typed. None of the animal isolates was of agr type III. A total of 12 out of 17 egc $3^{+}$human nasal isolates were of agr type III, the other 5 being agr type I. On the basis of representative multilocus sequence typing, agr type $\mathrm{III/egc3^{+ }}$ strains belonged to $\mathrm{CC} 30$. Human nasal isolates bearing an egc1 locus were distributed evenly across agr types I, II and III. Only two nasal isolates had an egc2 locus. All 14 agr type IV isolates, only 1 of which was of human origin, possessed an egc2 locus. The agr IV nasal isolate was fusidic acid sensitive and was found to be ST123 (CC121). There were strong associations between bovine, leporine and gallinaceous $S$. aureus clonal types and egc locus types. The PCR-RFLP procedure was used to screen an additional 45 S. aureus isolates from dogs, cats, rats, pigs and horses for egc locus types. Of these, 33 were $\mathrm{egc}^{-}$. Six equine isolates were selu ${ }^{+}$. One canine and three porcine isolates possessed

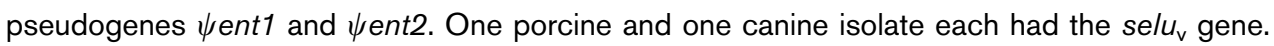
Putative relationships between disease-causing propensity and egc type need (re-)evaluation.

\section{INTRODUCTION}

Following the identification of the staphylococcal enterotoxins SEG and SEI by Munson et al. (1998), Monday \& Bohach (2001) and Jarraud et al. (2001) revealed that the genes encoding these enterotoxins were part of a chromosomal operon, termed the enterotoxin gene cluster

tPresent address: New York Medical College, Department of Microbiology and Immunology, Valhalla, NY 10595, USA.

Abbreviations: MLEE, multilocus enzyme electrophoresis; MLST, multilocus sequence typing; RAPD, randomly amplified polymorphic DNA.

The GenBank/EMBL/DDBJ accession numbers for the sequences of the egc loci genes of S. aureus are EU885488-EU885496. $(e g c)$, comprising five genes and two pseudogenes now

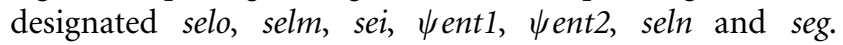
Subsequently, Letertre et al. (2003) demonstrated that some egc clusters possess an additional gene designated selu instead of the two pseudogenes, arising from a $15 \mathrm{bp}$ insertion in pseudogene $\psi$ ent 1 and a single adenine deletion that abolishes the pseudogene $\psi$ ent 1 stop codon.

Letertre et al. (2003) further reported that one isolate, $382 \mathrm{~F}$, harboured variant alleles of four genes, namely, $\operatorname{seg}_{\mathrm{v}}$, $s e i_{\mathrm{v}}, \operatorname{seln}_{\mathrm{v}}$ and $s e l u_{\mathrm{v}}$. The available egc sequence of strain 382F (GenBank accession no. AY158703) shows $100 \%$ identity with that of the egc locus of the genome-sequenced strain MRSA252 (GenBank accession no. NC_002952; 
Holden et al., 2004). Furthermore, the recently described selm $_{\mathrm{v}}$ gene (strain BK087, GenBank accession no. EF551341; Holtfreter et al., 2007) shows $100 \%$ identity with the corresponding gene in strain MRSA252. The selo gene of strain MRSA252 shows only $92 \%$ identity to that of the archetypal egc locus of strain A900322 (GenBank accession no. AF285760; Jarraud et al., 2001), confirming its status as a selo gene. Thus, three generally occurring egc loci have been described (genes/pseudogenes given in

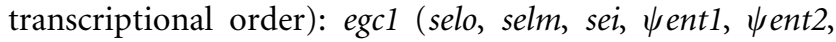
seln, seg), egc2 (selo, selm, sei, selu, seln, seg) and egc3 (selo $s e l m_{\mathrm{v}}, \operatorname{sei}_{\mathrm{v}}, \operatorname{selu}_{\mathrm{v}}, \operatorname{seln}_{\mathrm{v}}, s e \mathrm{~g}_{\mathrm{v}}$ ) (Fig. 1).

Thomas et al. (2006) observed further genetic variation within the egc locus. A recombination event between the selm and sei genes in strain A900624 produced a new gene designated selv (GenBank accession no. EF030427). In addition, a limited deletion event, namely, one adenine between the overlapping $5^{\prime}$ end of the $\psi$ ent 2 pseudogene and $3^{\prime}$ end of the $\psi$ ent 1 pseudogene, generated a novel gene, designated selu2, which differs from the selu and selu genes by the absence of the $15 \mathrm{bp}$ insert (GenBank accession no. EF030428). Based on the 3303 nt egc locus sequence of strain A900624 (kindly provided by $\mathrm{Dr}$ Damien Y. Thomas, AbAg, Technopolis, Île-de-France, France), this egc locus, herein designated egc4, has the genes selo, selv, selu2, seln and seg (Fig. 1).

Whilst there has been a plethora of reports on the occurrence of $e g c$ genes in strains of Staphylococcus aureus of human and animal origin (e.g. Becker et al., 2004; Chen et al., 2004; Omoe et al., 2005; Smyth et al., 2005; Boerema et al., 2006), few data exist on the relative occurrences of the selu or selu gene versus that of the $\psi$ ent 1 and $\psi$ ent 2 pseudogenes within the egc locus, let alone distinction of the selu $u_{\mathrm{v}}$ gene from the selu gene (Letertre et al., 2003; Blaiotta et al., 2004, 2006; Bania et al., 2006a, b; Chini et al., 2006; Thomas et al., 2006; Holtfreter et al., 2007; Nashev et al., 2007; Chiang et al., 2008). Moreover, whereas the SEG and SEI enterotoxins are emetic in monkeys (Munson et al., 1998), no comparative information is available on the emetic or superantigenic properties of variant enterotoxins. Accordingly, in assessing the potential role(s) of enterotoxins, enterotoxin-like proteins and their variants encoded by the egc locus in S. aureus-associated diseases and infections, distinction between the egc genotypes could potentially be important. The aims of the present study were to analyse the sei-seln intergenic regions of the egc loci of $S$. aureus of human nasal carriage and animal origins to determine the relative frequencies of occurrence of the

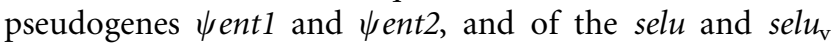
genes, and to assess whether there were any associations between agr type, egc locus type, enterotoxin and enterotoxin-like genotypes and molecular typing features.

\section{METHODS}

Bacterial strains and growth conditions. The fully genomesequenced S. aureus strains RF122 (egc2, ET3, ST151, CC151, Ridom

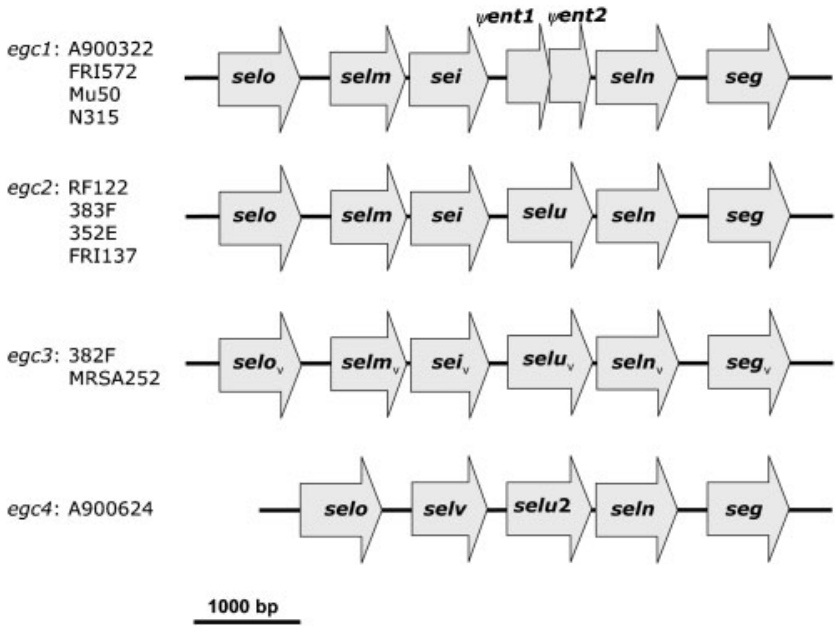

Fig. 1. Structure of the egc loci in $S$. aureus. Further details on the origins of strains, their years of isolation and literature references have been published previously (Collery \& Smyth, 2007). The egc1 sequence reported by Jarraud et al. (2001) is missing $69 \mathrm{nt}$, which was corrected by resequencing (Collery \& Smyth, 2007). The database sequences for strains 383F, 352E and FRI137 were incomplete with respect to the PSE1/PSE4-amplified region, and were completed as described previously based on the complete sequence for strain R122 (Collery \& Smyth, 2007). The sequences and their GenBank accession nos are: A900322 (AF285760 corrected by DQ993159), FRI157 (AF156894), Mu50 (BA000017), N315 (BA000018), RF122 (AJ938182), 383F (AY205306), 352E (AY205305), FRI137 (AY205307), 382F (AY158703), MRSA252 (BX571856) and A900624 (EF030427, EF030428; the $3303 \mathrm{nt}$ egc locus sequence of strain A900624 kindly provided by Dr Damien Y. Thomas). Collery \& Smyth (2007) have proposed that the selu2 gene of the egc4 locus be renamed the selw gene.

spa type t529, agr type II; Fitzgerald et al., 2001; Smyth, 2006; HerronOlson et al., 2007), Mu50 (egc1, ST5, CC5, Ridom spa type t002, agr type II, SCCmec type II; Kuroda et al., 2001; Kuhn et al., 2006), MRSA252 (Sanger 252, egc3, ST36, CC30, agr type III, EMRSA16, SCCmec type II; Holden et al., 2004; Kuhn et al., 2006) and NCTC8325-4 $\left(e g c^{-}\right)$, a derivative of strain NCTC8325 (ST8, CC8, agr type I, Ridom spa type t211), which is cured of prophages $\phi 11, \phi 12$ and $\phi 13$ (Novick, 1967; Iandolo et al., 2002), were used as control strains of known egc locus status. The latter three strains were kindly provided by T. J. Foster (Department of Microbiology, Trinity College Dublin). In addition, strain A900322 (egcl, selp, Ridom spa type t002), an isolate from a case of tampon-associated toxic shock syndrome, which yielded the archetypal egc locus sequence, was kindly provided by S. Jarraud (Université Lyon 1 , Centre National de Référence des Staphylocoques, Lyon, France) (Jarraud et al., 2001; Blaiotta et al., 2006). Strain AB-8802 ( $s e g_{v}, s e i_{v}$, Ridom spa type t021), originally isolated from raw poultry meat, was kindly supplied by $\mathrm{G}$. Blaiotta (Dipartimento di Scienza degli Alimenti, Università degli Studi di Napoli 'Federico II', Portici, Italy) (Blaiotta et al., 2004, 2006). S. aureus NCTC 6571 (Oxford strain) was used as a control strain in disc sensitivity tests with $10 \mu$ g fusidic acid discs (Oxoid).

A total of $43 \mathrm{egc}^{+}$human nasal isolates, 41 of which have been shown previously to harbour the five common egc genes (selo, selm, sei, seln 
Table 1. Known characteristics of human nasal and animal isolates of $S$. aureus

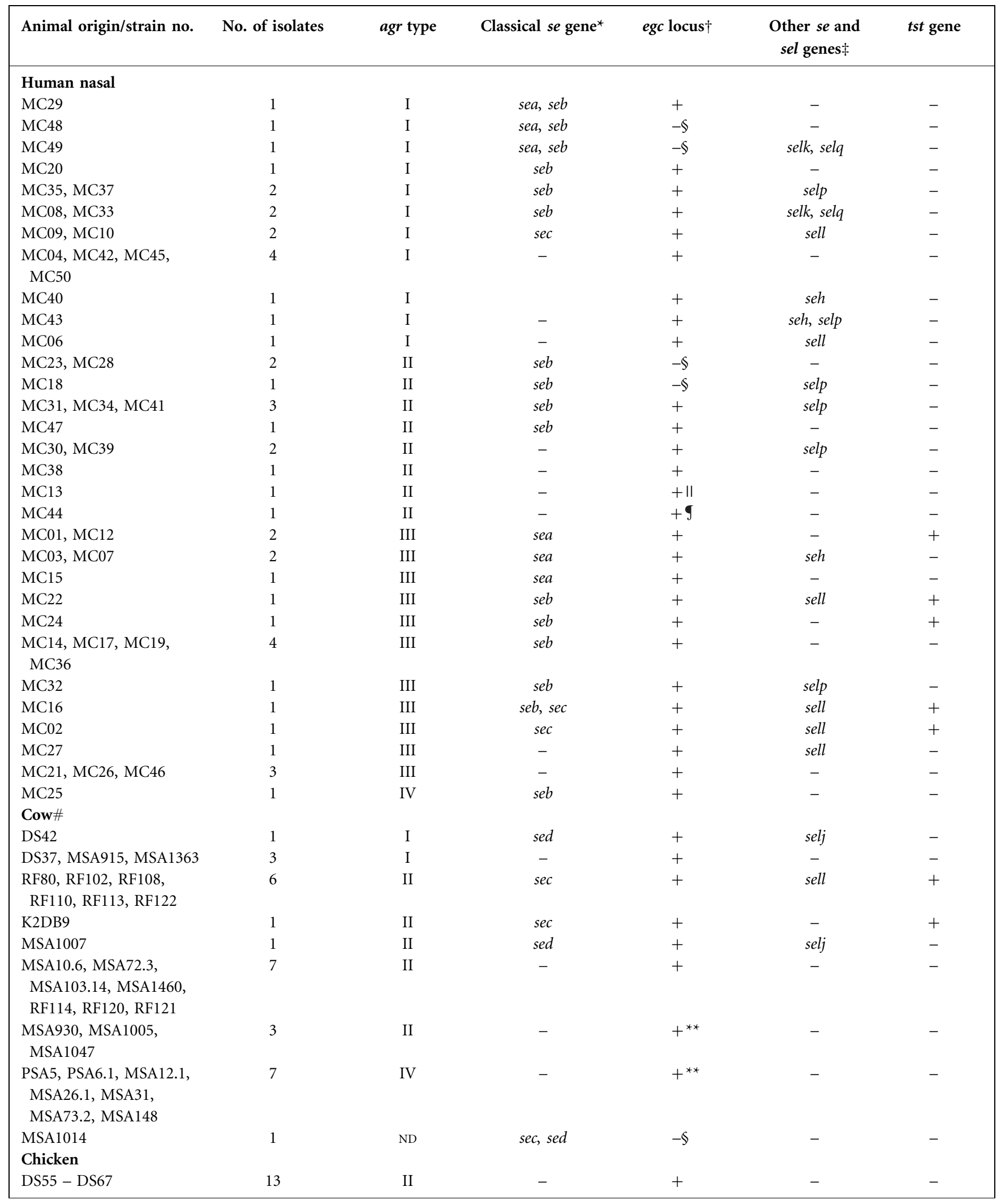


Table 1. cont.

\begin{tabular}{|lcccc|}
\hline Animal origin/strain no. & No. of isolates & agr type & Classical se gene & $\begin{array}{c}\text { egc locus } \dagger \\
\text { Other se } \text { and } \\
\text { sel genes } \ddagger\end{array}$ \\
\hline $\begin{array}{l}\text { Rabbit } \\
\text { DS31, DS44, DS45, DS46, }\end{array}$ & 5 & IV & - & + \\
DS53 & & & - & - \\
Sheep & 2 & II & - & - \\
DS97, DS95 & 1 & IV & - & - \\
DS103 & & I & + & - \\
Goat & 3 & & - \\
DS26, DS27, DS30 & & & - \\
\hline
\end{tabular}

ND, Not determined.

${ }^{*}$ Screened for the $s e a, s e b$, sec, sed and see genes.

$\dagger$ Screened for the egc locus genes seg, sei, selm, seln and selo.

$¥$ Screened for the seh, selj, selk, sell and selq genes.

Segc control isolates.

$\|$ egc locus missing the sei gene, i.e. gene not detected by PCR.

$\checkmark$ egc locus missing the seln and selo genes, i.e. gene not detected by PCR.

\#RF isolates are from Ireland, MSA and PSA isolates are from the USA, DS42 is from Argentina, K2DB9 is from Denmark and DS37 is from Spain.

${ }^{*}$ egc locus missing the seg gene, i.e. not detected by PCR.

and seg, referred to herein as a 'complete' locus) and 2 which were 'missing' (i.e. the genes were not detected by PCR) the sei gene, and the seln and selo genes, respectively (referred to herein as an 'incomplete' locus), were included (Collery et al., 2008) (Table 1). In addition, five human nasal isolates lacking the egc locus were included as negative controls (Table 1). All isolates had been confirmed as S. aureus as described previously (Collery et al., 2008).

A total of $53 \mathrm{egc}^{+}$isolates of $S$. aureus from cows $(n=29)$, goats $(n=3)$, chickens $(n=13)$, rabbits $(n=5)$ and sheep $(n=3)$ from the study of Smyth et al. (2005) were used (Table 1). Of these animal isolates, 42 had a complete egc locus (33 of these possessed only the egc locus) and 11 (10 from cows and 1 from a sheep) had an incomplete egc locus. Of the bovine isolates, 9 were from the Republic of Ireland, 17 were from the USA and 1 each was from Argentina, Denmark and Spain. All of the chicken isolates were from Northern Ireland. The three goat isolates were from Italy. Two of the sheep isolates were from Denmark and one was from Sweden. Of the rabbit isolates, four were from Belgium and one was from Spain. Bovine isolate MSA1014 from the USA (Table 1) was used as an egc control animal strain. All isolates had been confirmed as $S$. aureus as described previously (Smyth et al., 2005).

A further 44 fresh $S$. aureus isolates were obtained from animals courtesy of N. Leonard (Veterinary School, University College Dublin, National University of Ireland, Dublin, Republic of Ireland). A total of 3 isolates were from cats $(1$ nasal isolate and 2 from wounds), 6 from dogs ( 2 from skin, 2 nasal isolates and 2 from wounds), 28 from horses ( 26 nasal isolates, 1 from a wound and 1 from a joint), 3 from rats (nasal isolates) and 4 from pigs ( 3 nasal isolates and 1 from a joint). The identification of these isolates was confirmed by Gram staining, a tube coagulase test, the API ID32 Staph system (bioMérieux) and the detection of clumping factor, protein A and capsular polysaccharide using a Pastorex Staph Plus latex agglutination kit (Bio-Rad Laboratories). In addition, an $S$. aureus isolate from a cat was obtained from E. Olsson (Swedish Zoonosis Centre, National Veterinary Laboratory, Uppsala, Sweden).
DNA extraction. Preparation of genomic DNA from S. aureus was performed as described previously (Fitzgerald et al., 1997). The procedure involved lysostaphin lysis, proteinase $\mathrm{K}$ treatment, addition of EDTA, sarkosyl and cetyltrimethylammonium bromide, extraction with chloroform: isoamyl alcohol and phenol:chloroform: isoamyl alcohol, and precipitation with ethanol. The quantity and quality of the extracted DNA were checked by running $1 \mu \mathrm{l}$ DNA preparation on a $1 \%(\mathrm{w} / \mathrm{v})$ agarose gel alongside DNA standards of known concentration (2 log DNA ladder; Promega).

PCR. The sets of primers used for detection of the selu or selu gene

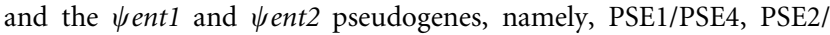
PSE4 and PSE2/PSE6, have been described by Letertre et al. (2003) and were used according to Collery \& Smyth (2007). The primer set PSE1/PSE4 was designed to amplify the egc locus region encoding the pseudogenes $\psi e n t 1$ and $\psi e n t 2$, and either the selu or seluv gene from the stop codon of the sei gene to the first $172 \mathrm{nt}$ of the $5^{\prime}$ end of the seln gene, yielding amplimers of 1134 and $1148 \mathrm{bp}$, respectively. Nucleotides $13-27$ of the $27 \mathrm{nt}$ primer PSE2 matched the specific $15 \mathrm{nt}$ insert in the selu and selu $\mathrm{v}_{\mathrm{v}}$ genes. PCR assays with the primer sets PSE2/PSE4 and PSE2/PSE6 yielded amplimers of 790 and $142 \mathrm{bp}$, respectively, when either the selu or the seluv gene was present. DNA preparations from strains A900322, Mu50, RF122, MRSA252 and NCTC8325-4 were run as controls as appropriate.

The primers Sei_rev-RC (5'-CAGGAGATGGACTGCCTG- $\left.3^{\prime}\right)$ and Seln_for-RC ( $5^{\prime}$-GCAGCTATGTAGAACAATCTCATAAGC-3') were designed to amplify the region between the sei and seln genes when the primers PSE1 and PSE4 were unable to generate a PCR product. These primers were the reverse complements of the two primers originally described by Monday \& Bohach (1999) and Smyth et al. (2005) for amplification of the sei and seln genes, respectively. By taking the reverse complements of the $3^{\prime}$ sei primer and the $5^{\prime}$ seln primer, these primers annealed outwards from the genes they were originally designed to amplify and were orientated towards each other to amplify the sei-seln intergenic region, yielding an amplimer of 1095 bp. The PCR conditions used for these primers were 45 cycles of 
$94{ }^{\circ} \mathrm{C}$ for $30 \mathrm{~s}, 62{ }^{\circ} \mathrm{C}$ for $30 \mathrm{~s}$ and $72{ }^{\circ} \mathrm{C}$ for $30 \mathrm{~s}$. In addition, the SEU-1 and SEU-2 primers described by Nashev et al. (2007) were tested for amplification within the egc loci using the PCR conditions of these authors.

Based on gene alignments for strains RF122, 352E, FRI137 and 383F $\left(\right.$ selu $\left.^{+}\right)$, and strains MRSA252 and 382F $\left(\right.$selu $\left._{\mathrm{v}}{ }^{+}\right)$, a region with ten conserved nucleotide differences between the selu and selu genes was identified between nt 440 and 520 (Table 2). However, it is important to note that the only difference between the seluv sequences in this discriminatory intragenic region and the pseudogene $\psi$ ent 1 and $\psi$ ent 2 sequences of strains Mu3, Mu50, N315 and A900322 is a T479 $\rightarrow$ A465 transversion (corresponding nucleotide positions in the alignment). To distinguish isolates bearing either the selu or seluv gene, universal primers that amplified between nt 382 and 584 of the selu and seluv genes were designed: selu(v)-for (5'-AAAACGTGTATGTATGGCG$\left.3^{\prime}\right)$ and selu(v)-rev (5'-TTATGCTTAAGTAAATAGTTTCTAACTTTATC- $\left.3^{\prime}\right)$.

An agr group-specific multiplex PCR was performed using the primers and thermal cycling conditions described by Gilot et al. (2002). With the exception of strain RF122 (agr type II) (Fitzgerald et al., 2000), the following agr control strains were provided by T. J. Foster and A. Rossney (National MRSA Laboratory, St James's Hospital, Dublin, Republic of Ireland): strains Newman, COL and NCTC8325-4 (agr type I); strains MRSA252 and MW2 (agr type III); and strain RN4850 (agr type IV).

The standard nomenclature for SE and SEl gene designations recommended by Lina et al. (2004) has been used throughout. All of the previously characterized human and animal isolates have been screened for the $15 \mathrm{SE}$ and SEl genes sea-see, seg-sei, selj-selo and selq, and for the tst gene using multiplex and singleplex PCR protocols (Smyth et al., 2005; Collery et al., 2008). The human nasal isolates and isolates from chickens, goats, sheep and rabbits were further screened for the selp gene using primers and PCR conditions described by van Wamel et al. (2006).

In silico analyses of the sei-seln intergenic regions of egc loci bearing selu and selu $u_{\mathbf{v}}$ genes. FASTA files of DNA sequences of $e g c$ loci containing selu and selu $u_{\mathrm{v}}$ genes were retrieved from the National Center for Biotechnology Information nucleotide database. PSE1/ PSE4-amplified sequences were analysed using RestrictionMapper version 3 (http://www.restrictionmapper.org) to identify restriction

Table 2. Nucleotides differences between selu and selu $u_{v}$ genes and pseudogenes $\psi$ ent1 and $\psi$ ent2 of reference $S$. aureus strains

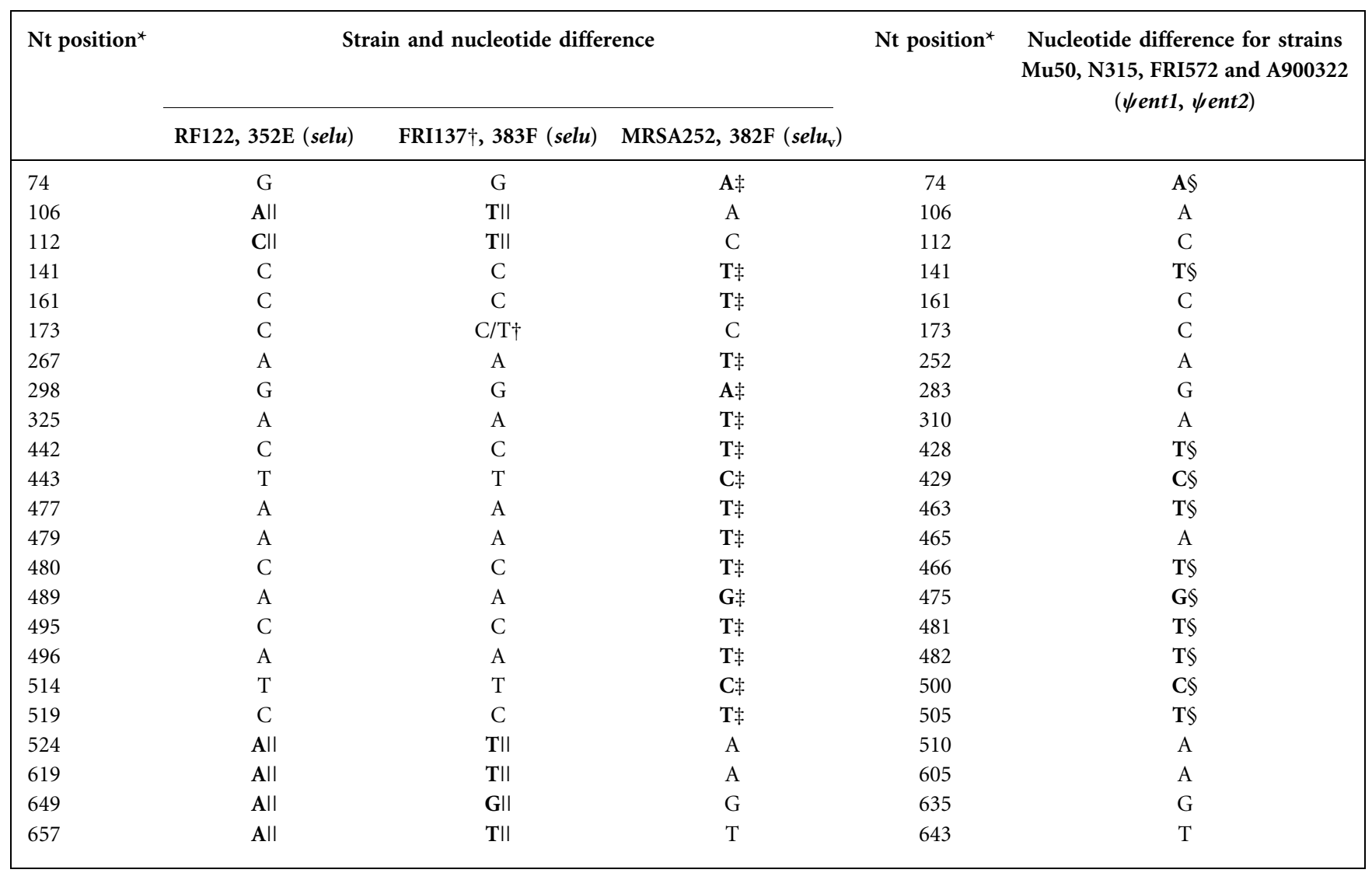

${ }^{*}$ Nucleotides numbered with respect to the start codons of the selu and $s e l u_{\mathrm{v}}$ genes and pseudogene $\psi e n t 1$; the $s e l u$ and $s e l u_{\mathrm{v}}$ gene sequences differ from pseudogene $\psi e n t 1$ and $\psi$ ent 2 sequences by the insertion of $15 \mathrm{nt}$ after $\mathrm{nt} 218$ of pseudogene $\psi$ ent 1 and a single adenine deletion corresponding to nt 371 of pseudogene $\psi$ ent 1 that abolishes the pseudogene $\psi$ ent 1 stop codon.

$\dagger$ Strain FRI137 differs at nt 173 from all other reference strains by a $\mathrm{C} \rightarrow \mathrm{T}$ transition.

$\$$ Nucleotide sequence differences of $s e l u_{\mathrm{v}}{ }^{+}$strains MRSA252 and 382F from selu ${ }^{+}$strains RF122, 352E, FRI137 and $383 \mathrm{~F}$.

$\$$ Shared nucleotide sequence differences of pseudogene $\psi e n t 1$ and $\psi e n t 2$ strains and $s e l u_{\mathrm{v}}{ }^{+}$strains from the four selu ${ }^{+}$strains RF122, 352E, FRI137 and $383 \mathrm{~F}$.

IINucleotide sequence differences between selu ${ }^{+}$strains RF122 and 352E and selu ${ }^{+}$strains FRI137 and 383F. 
enzyme cleavage sites. The CLC Free Workbench software version 4.5.1 (http://www.clcbio.com) was used to align DNA sequences of the PSE1/PSE4 amplimers of egc loci.

PCR-RFLP analysis of PSE1/PSE4-amplified PCR products of the egc locus. The PCR-RFLP procedure of Collery \& Smyth (2007) was used. Endonuclease HindIII cleaves PSE1/PSE4 amplimers

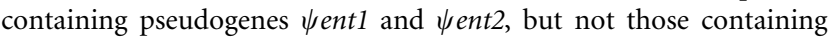
either the selu or $s e l u_{\mathrm{v}}$ gene. In contrast, endonuclease HphI cuts PSE1/PSE4 amplimers containing either the selu or selu gene, but not

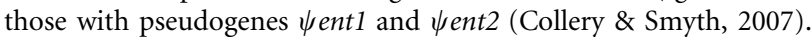

For PCR-RFLP analysis using endonuclease BbvI cleavage of PSE1/ PSE4 amplimers containing selu and selu $u_{\mathrm{v}}$ genes, the standard reaction mixture was modified to contain $3 \mu \mathrm{l} 10 \times$ NEBuffer $2[50 \mathrm{mM} \mathrm{NaCl}$, $10 \mathrm{mM}$ Tris/HCl (pH 7.9), $10 \mathrm{mM} \mathrm{MgCl}, 1 \mathrm{mM}$ DTT; NEB] and $1 \mu \mathrm{l} B b v \mathrm{I}$ restriction endonuclease $\left(2 \mathrm{U} \mu \mathrm{l}^{-1} ; \mathrm{NEB}\right)$. The $B b v \mathrm{I}$ digestion mixture was incubated overnight at $37^{\circ} \mathrm{C}$. For TseI digestion of PSE1/PSE4 amplimers containing selu and selu genes, the incubation was performed at $65^{\circ} \mathrm{C}$. The standard reaction mixture contained $3 \mu \mathrm{l}$ NEBuffer $3[100 \mathrm{mM} \mathrm{NaCl}, 50 \mathrm{mM}$ Tris/HCl (pH 7.9), $10 \mathrm{mM} \mathrm{MgCl}, 1 \mathrm{mM}$ DTT; NEB] and $1 \mu \mathrm{T}$ Tsel restriction

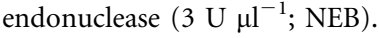

Sequencing of selu genes and intragenic selu or selu amplimers. Two selu ${ }_{\mathrm{v}}{ }^{+}$isolates identified in this study by PCRRFLP analysis of PSE1/PSE4 amplimers of the egc locus, comprising human nasal isolate MC15 (ST30, agr type III) belonging to MLVA population IIa (Collery et al., 2008) and strain AB-8802 (Blaiotta et al., 2004), were selected for gene sequencing to confirm their status. PCR was carried out using the PSE1/PSE4 primer pair of Letertre et al. (2003) with Taq DNA polymerase. Intragenic 203 bp PCR products using primers selu(v)-for/selu(v)-rev were obtained for strains MC15, MC20, MC40 and MSA1047. These were purified using a High Pure PCR product purification kit (Roche) and sequenced by GATC Biotech.

The derived sequences were aligned with selu gene sequences from GenBank of strains RF122 (bovine mastitis; GenBank accession no. NC_007622), 352E (farm fromage frais; GenBank accession no. AY205305), 383F (rice salad; GenBank accession no. AY205307) and FRI137 (thigh abscess, Ridom spa type t352; GenBank accession no. AY205306), and with selu vene sequences of strains MRSA252 (postoperative infection; GenBank accession no. NC_002952) and 382F (water, Ridom spa type t166; GenBank accession no. AY158703), and with $\psi$ ent 1 and $\psi$ ent 2 pseudogene sequences of strains Mu50 (surgical wound; GenBank accession no. NC_002758), N315 (pharyngeal smear; GenBank accession no. NC_002745), FRI572 (nasal isolate, Easter Island; GenBank accession no. AF156894) and A900322 (tampon isolate; GenBank accession no. AF285760 as corrected by DQ993159) using the CLC Free Workbench software version 4.5.1.

\section{RESULTS AND DISCUSSION}

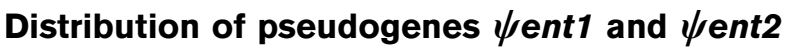 and the selu or selu $u_{v}$ gene among $\operatorname{egc}^{+} S$. aureus isolates of human and animal origin}

Using the PCR primer sets PSE1/PSE4, PSE2/PSE4 and PSE2/PSE6 (Letertre et al., 2003), the genome-sequenced control strains Mu50 (egc1), RF122 (egc2) and MRSA252 (egc3), and the archetypal egc ${ }^{+}$strain A900322 (egc1) yielded amplimers consistent with their known egc locus status. Neither DNA from control strain NCTC8325-4 $\left(e g c^{-}\right)$nor DNA from the five human nasal isolates (MC18,
MC23, MC28, MC48 and MC49) and the one bovine isolate (MSA1014) lacking an egc locus gave amplimers with any of these primer pairs.

Of the $43 \mathrm{egc}^{+}$human nasal isolates, 18 had either the selu or the seluv gene, and 16 had the pseudogenes $\psi$ ent 1 and went2. The nine remaining isolates, seven with a complete egc locus and two with incomplete egc loci (MC13 missing the sei gene and MC44 missing the seln and selo genes) either failed to yield amplimers or did not yield amplimers of the expected size of $\sim 1150 \mathrm{bp}$ with the PSE1/PSE4 primer pair, despite repeated attempts, even after adjustments to the PCR conditions. Anomalously sized PSE1/ PSE4 amplimers of $\sim 500 \mathrm{bp}$ (three isolates), $\sim 1100 \mathrm{bp}$ (two isolates) and $\sim 3000 \mathrm{bp}$ (four isolates) were occasionally but not reproducibly obtained. Blaiotta et al. (2006) also reported obtaining odd-sized amplimers using the primers of Letertre et al. (2003) with both human and food isolates of $S$. aureus belonging to their restriction endonuclease analysis egc groups 1 and 4, both of which

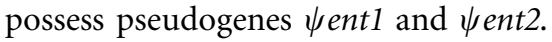

The nine isolates that were refractory to yielding PSE1/PSE4 amplimers were rechecked for the presence of the sei and seln genes with individual primer pairs (Smyth et al., 2005), with positive findings in all expected instances. Primers Sei_rev$\mathrm{RC}$ and Seln_for-RC were used as an alternative strategy to amplify the sei-seln intergenic regions of these PSE1/PSE4refractory isolates. Control strains MRSA252, Mu50 and RF122 yielded amplimers of $\sim 1100 \mathrm{bp}$. This approach, followed by sequencing of the resulting amplimers, resolved the nature of the egc loci of a further two nasal isolates MC14 (595 nt alignment; GenBank accession no.

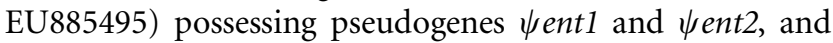
MC33 (618 nt alignment; GenBank accession no. EU885494) harbouring the selu gene. The SEU-1 and SEU-2 primers of Nashev et al. (2007) were utilized with the remaining seven isolates in a further attempt to obtain amplimers suitable for sequencing. Strain MRSA252, used as a positive control, yielded an amplimer of the expected size of $\sim 500 \mathrm{bp}$, but the seven test nasal carriage strains did not. Of these refractory isolates, two were ST6 and ST932, both belonging to CC6 and of agr type I, one was ST937, a singleton and agr type II, and one was ST933, belonging to CC30 and of agr type III. Of the remaining three isolates, one was of agr type I and two were of agr type II, none of which had been typed by multilocus sequence typing (MLST).

Thus, $19 / 43$ (44.2\%) $\mathrm{egc}^{+}$human nasal isolates were confirmed as possessing either the selu or the seluv gene, and $17(39.5 \%)$ had the pseudogenes $\psi$ ent 1 and $\psi$ ent 2 . The recalcitrant isolates may have mutations or insertion sequences (Rve-like 1-transposase 8 and Rve-like 2-IstBlike; Thomas et al., 2006) in their sei-seln intergenic sequences, or they may have deletions in their sei-seln intergenic regions or may genuinely lack the selu or selu

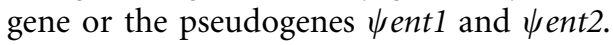

A total of 28 of the $53 \mathrm{egc}^{+}$bovine, ovine, caprine, leporine and gallinaceous isolates possessed either the selu or seluv 
gene, and 25 isolates possessed the pseudogenes $\psi$ ent 1 and $\psi$ ent2. The frequencies of either the selu or selu gene for isolates from the different animal species were: cows (21/ $29,72.4 \%)$, goats $(0 / 3,0 \%)$, rabbits $(5 / 5,100 \%)$, sheep ( $2 /$ $3,67 \%)$ and chickens $(0 / 13,0 \%)$, whilst the remainder

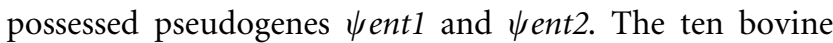
isolates and one ovine isolate that had previously been shown to have an egc locus with a missing seg gene by PCR tests (Table 1) (Smyth et al., 2005) all had either the selu or selu $u_{\mathrm{v}}$ gene. Strain AB-8802 from raw poultry meat was found to be either selu ${ }^{+}$or seluv ${ }^{+}$.

To verify the nature of the egc locus in the human and animal isolates, the PCR-RFLP differential endonuclease susceptibility assay developed by Collery \& Smyth (2007) was employed. Control strains A900322, Mu50, RF122 and MRSA252 gave the expected differential endonuclease fragment profiles (Collery \& Smyth, 2007). PSE1/PSE4 amplimers from the animal isolates and human nasal isolates that were pseudogene-positive were cleaved by restriction enzyme HindIII, but not by endonuclease $H p h I$. In contrast, all PSE1/PSE4 amplimers from the animal and human nasal isolates bearing either the selu or selu gene were cleaved by endonuclease $H p h \mathrm{I}$, but not by endonuclease HindIII. Strain AB-8802 was confirmed as either selu $^{+}$or selu $_{\mathrm{v}}{ }^{+}$on the basis of PCR-RFLP analysis.

Few studies have reported the relative frequencies of egc genotypes among S. aureus isolates (Bania et al., 2006a; Chini et al., 2006; Vancraeynest et al., 2006a). However, none of these studies differentiated their 'selu'-containing loci as either $e g c 2$ or $e g c 3$, and accordingly reference to an egc2 locus in these publications should be taken to infer an egc2 or egc3 locus $\left(\right.$ selu $^{+}$or selu ${ }^{+}$). Thomas et al. (2006) reported the egcl locus in 409/421 isolates (97.1\%) of nasal and infection origins having at least one egc-associated gene. However, the forward (yent1: 5' ACGTAGATTTGTTTGGGACAAACT-3') and reverse (yent2: 5'-GTGCTGTTATGTTTTTCTTATTAGTAGG-3') primers used by these authors have $100 \%$ sequence matches for egcl, egc3 and egc4 loci sequences of strains Mu50 $\left(\psi e n t 1^{+} \psi_{\text {ent }}{ }^{+}\right)$, MRSA252 $\left(\right.$selu $\left._{\mathrm{v}}{ }^{+}\right)$and A900624 $\left[\right.$ selu $2^{+}\left(\right.$selw $\left.\left.^{+}\right)\right]$, respectively. In the case of selu sequences, whilst primer yent 1 matches those in the National Center for Biotechnology Information database for egc2 loci, the 28 nt yent 2 reverse primer has a $3^{\prime}$-end G/T mismatch with the sequences for strains RF122, 352E, 383F and FRI137. For primers with $\mathrm{T}, \mathrm{C}$ or $\mathrm{G}$ as the $3^{\prime}$ nucleotide, Taq DNA polymerase is highly specific for template complementarity to this base and, because it lacks $3^{\prime} \rightarrow 5^{\prime}$ exonuclease activity, this enzyme cannot correct mismatches at the primer 3' terminus (Ayyadevara et al., 2000). Nonetheless, some primers with $3^{\prime}$-end G/T mismatches have been demonstrated to be as efficient in PCR as the normal primer with a $3^{\prime}$-end G/C match (Simsek \& Adnan, 2000). Thus, it is seems entirely possible that many of the 409 isolates of Thomas et al. (2006) purported to possess an egc1 locus may in fact have an egc3 locus, or possibly even an egc2 locus.

\section{Occurrence of selu and selu genes among human nasal and animal $S$. aureus isolates}

At the time of this investigation, the only method for distinguishing the selu and selu genes was DNA sequencing. The DNA sequences of the selu genes of strains RF122 and $352 \mathrm{E}$ are identical, and differ from the selu gene sequences of strains FRI137 and 383F at six nucleotide positions (Table 2). In contrast, whilst the sequences of the selu $v_{\mathrm{v}}$ genes of strains MRSA252 and 382F are identical, they differ from those of the 4 annotated selu genes at 16 conserved nucleotide positions (Table 2). Whilst 11 of these $s^{2} l u_{\mathrm{v}}$ nucleotide differences are shared with pseudogenes $\psi e n t 1$ and $\psi e n t 2$, it seemed that it might be possible to distinguish the selu gene from the selu gene on the basis of differential endonuclease susceptibility, as has been achieved for pseudogenes $\psi$ ent 1 and $\psi$ ent 2 , and either a selu or selu $\mathrm{v}_{\mathrm{v}}$ gene (Chini et al., 2006; Collery \& Smyth, 2007).

The PSE1/PSE4-amplified sequences bearing the abovementioned six reference selu and selu genes were analysed using the RestrictionMapper 3 program in comparison with known PSE1/PSE4-amplified sequences bearing the

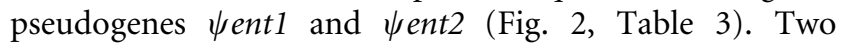
endonucleases yielded promising in silico findings, namely, $B b v \mathrm{I}$ and TseI. Whilst these endonucleases do not distinguish strains with egc loci bearing pseudogenes $\psi$ ent 1 and $\psi$ ent 2 from those bearing the $s e l u_{\mathrm{v}}$ gene, both enzymes
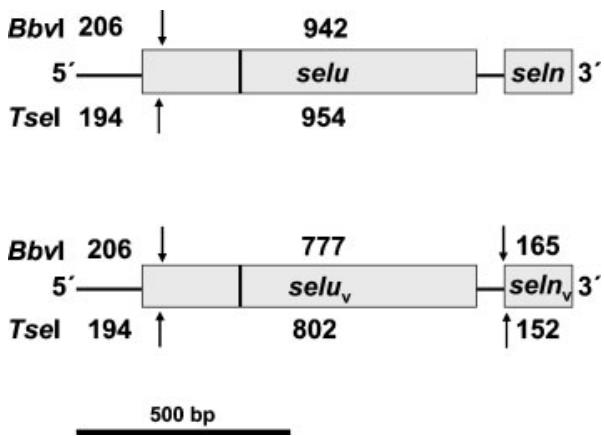

Fig. 2. Schematic diagram of PSE1/PSE4-amplified PCR amplimers bearing the selu or selu $v_{v}$ gene, showing the cleavage sites for restriction endonucleases $\mathrm{Bbvl}$ and Tsel (indicated by arrows) above and below each PCR product diagram, respectively, with the sizes of the fragments in bp. The black bars shown within the selu and seluv genes correspond to the signature $15 \mathrm{bp}$ insert in the $\psi$ ent 1 pseudogene. The 5 '-cleavage site for Tsel is between nucleotides G-41 and C-42 of the selu and seluv genes yielding a $194 \mathrm{bp}$ fragment, and that for $\mathrm{Bbvl}$ is between T-53 and T-54 of the selu and seluv genes yielding a 206 bp fragment. An additional $B b v l$ cleavage site lies between T-7 and T-8 of the $s e / n_{v}$ gene. For $T$ sel, this additional site lies between G-19 and C-20 of the seln gene. Thus, the distinction of selu-bearing from selu $u_{\mathrm{v}}$-bearing PSE1/PSE4 sequences is made possible by the co-occurrence of variant genes in the egc3 cluster (Letertre et al., 2003; Blaiotta et al., 2004; Holden et al., 2004; Holtfreter et al., 2007). 
Table 3. In silico analysis of restriction endonuclease cleavage of the sei-seln intergenic sequences of the egc locus between primers PSE1 and PSE4 in strains known to possess egc1, egc2 and egc3 loci

\begin{tabular}{|c|c|c|c|}
\hline \multirow[t]{2}{*}{ Restriction endonuclease } & \multicolumn{3}{|c|}{ Size (bp) of restriction fragments of PSE1/PSE4 regions for the indicated strains ${ }^{\star}$} \\
\hline & $\begin{array}{c}\text { A900322/Mu50/N315/FRI572 } \\
(1135 \mathrm{nt} \text { egc1 })\end{array}$ & $\begin{array}{c}\text { RF122/352E/FRI137/383F } \\
(1149 / 1150 \mathrm{nt} e g c 2) \dagger\end{array}$ & 382F/MRSA252 (1149 nt selu $)$ \\
\hline \multirow[t]{3}{*}{$B b v \mathrm{I}$} & 763 & 942 & 777 \\
\hline & 206 & $206 / 207 \dagger$ & 206 \\
\hline & 165 & & 165 \\
\hline \multirow[t]{3}{*}{ TseI } & 788 & 954 & 802 \\
\hline & 194 & $194 / 195 \dagger$ & 194 \\
\hline & 152 & & 152 \\
\hline
\end{tabular}

${ }^{\star}$ For GenBank accession numbers see Fig. 1.

$\dagger$ The second value is that for restriction fragments of strain 383F, the PSE1/PSE4 amplimer of which is 1 nt longer due to the insertion of a thymine in the sei-selu intergenic region between T-68 and T-70.

exhibit differential cleavage of PSE1/PSE4-amplified sequences from $e g c 2^{+}$and $e g c 3^{+}$strains, the selu-bearing sequence yielding two fragments and the selu $u_{\mathrm{v}}$-bearing sequence yielding three fragments with both enzymes (Table 3). The presence of a 942 or $954 \mathrm{bp}$ fragment in endonuclease-cleaved PSE1/PSE4-amplified sequences from selu ${ }^{+}$isolates in contrast to 777 and 165 bp or 802 and 152 bp fragments in endonuclease-cleaved PSE1/PSE4amplified sequences from selu ${ }_{\mathrm{v}}{ }^{+}$isolates can be used to distinguish the egc2 and egc3 loci (Fig. 2, Table 3), provided that a 'selu'-type gene has been shown to be present using the primers of Letertre et al. (2003).

To test the in silico findings, PSE1/PSE4 amplimers from the genome-sequenced strains RF122 (selu) and MRSA252 $\left(s^{2} l u_{\mathrm{v}}\right)$ were digested with endonucleases $B b v \mathrm{I}$ and TseI. In both cases, the endonucleases allowed distinction according to the in silico criteria. The PSE1/PSE4 amplimers for the 28 animal and 18 human isolates possessing either a selu or selu $u_{\mathrm{v}}$ gene were cut using BbvI. Of the 18 human nasal isolates, only two had a selu gene (egc2 locus).

Regarding the 16 selu $_{\mathrm{v}}{ }^{+}\left(e g c 3^{+}\right)$human nasal isolates identified by PCR-RFLP and the single $\operatorname{selu}_{\mathrm{v}}{ }^{+}$isolate identified by PCR with reverse complement primers, 5 were of agr type I (MC08, MC33, MC35, MC37 and MC42 - none of these had been MLST typed), 4 of which were $s b^{+}$( 2 of these having in addition the selk and selq genes and 1 the selp gene), and 12 were of agr type III (MC01, MC03, MC07, MC12, MC15, MC17, MC19, MC24, MC26, MC27, MC36 and MC46), 5 of which had the sea gene (2 in addition to the seh gene and 2 with the tst gene) and 4 of which had the seb gene ( 1 in addition to the tst gene). Of the three $\mathrm{egc3}^{+}$isolates of agr type III that lacked a classical enterotoxin-encoding gene, one possessed the sell gene.

All 28 of the bovine, ovine and leporine isolates had the selu gene. Of these, 20 (13 from cows, 5 from rabbits and 2 from sheep) had only an egc locus, 11 of which (bovine and ovine) were missing the seg gene (Smyth et al., 2005). Of the remaining eight bovine isolates, six also possessed the pathogenicity island SaPIbov (sec, sell, tst), one had the sec and tst genes, and one had the sed and selj genes (Fitzgerald et al., 2001; Smyth et al., 2005). Strain AB-8802 was found to possess the seluv gene.

To confirm the identity of the selu genes, PSE1/PSE4 amplimers of two $s e l u_{\mathrm{v}}{ }^{+}$isolates, human nasal isolate MC15 (Collery et al., 2008) and strain AB-8802 (Blaiotta et al., 2004), were selected for single-strand sequencing. When these sequences were compared with the selu gene sequences of strains RF122, 352E, 383F and FRI137, and with the $s e l u_{\mathrm{v}}$ gene sequences of strains MRSA252 and 382F, strain AB-8802 (680 nt alignment; GenBank accession no. EU885493) and isolate MC15 (668 nt alignment; GenBank accession no. EU885496) gave $100 \%$ matches to those of the selu $u_{\mathrm{v}}$ genes.

Based on gene alignments for strains RF122, 352E, FRI137 and 383F $\left(\right.$ selu $\left.^{+}\right)$, and strains MRSA252 and 382F $\left(\right.$selu $\left._{\mathrm{v}}{ }^{+}\right)$, 10 of the 16 conserved nucleotide differences between the selu and seluv genes occurred between nt 440 and 520 (Table 2). Universal primers designed to amplify a $203 \mathrm{bp}$ fragment encompassing the $80 \mathrm{bp}$ selu/selu $\mathrm{v}_{\mathrm{v}}$ discriminatory intragenic region were used to obtain PCR products for control strains MRSA252, RF122 and Mu50, for four nasal

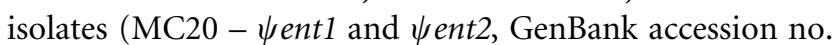
EU885488; MC40 - selu, GenBank accession no. EU885489; and MC15 and MC36 - seluv, GenBank accession nos EU885490 and EU885492, respectively) and for one bovine strain (MSA1047 - selu, GenBank accession no. EU885491). The sequences obtained were aligned with those of the reference selu strains RF122 and FRI137, reference selu $u_{\mathrm{v}}$ strain MRSA252, and reference $\psi$ ent1 and Went 2 pseudogene sequences of strains Mu50, N315, FRI572 and A900322. Although the obtained sequences varied in length (127-145 nt), all included eight of the ten target differential nucleotides from nt 477 to 519. These alignments confirmed the identity of the test strains as 
Table 4. Distribution of the pseudogenes $\psi e n t 1$ and $\psi e n t 2$ (egc1), the selu gene (egc2) and the seluv gene (egc3) among animal and human nasal isolates of $S$. aureus

\begin{tabular}{|c|c|c|c|c|c|c|c|}
\hline \multirow[t]{2}{*}{ agr type } & \multicolumn{4}{|c|}{ No. in human nasal isolates } & \multicolumn{3}{|c|}{ No. in animal isolates } \\
\hline & $\operatorname{egcl}{ }^{\star}$ & $\operatorname{egc} 2 \dagger$ & egc $3 \ddagger$ & $\begin{array}{c}\text { egc not } \\
\text { determined }\end{array}$ & $\operatorname{egcl} \S$ & $\operatorname{egc} 2 \|$ & egc3 \\
\hline I & 6 & 1 & 5 & 3 & 6 & 1 & 0 \\
\hline II & 6 & 0 & 0 & 3 & 19 & 14 & 0 \\
\hline III & 5 & 0 & 12 & 1 & 0 & 0 & 0 \\
\hline
\end{tabular}

${ }^{*}$ Of the agr type I isolates, three had the sell gene (two of which also had the $s e c$ gene), one had the seb gene and two were egc only; of the agr type II isolates, three possessed the seb gene and three were egc only; of the agr type III isolates, three had the seb gene (one in addition to the sell and tst genes), one the sec, sell and tst genes, and one was egc only.

$\dagger$ The agr type I isolate also had the seh gene, whilst the agr type IV isolate also possessed the seb gene.

‡Of the agr type I isolates, one was egc only and four possessed the seb gene (two of which had the selk and selq genes in addition); of the agr type III isolates, two were $e g c$ only, one had the egc locus plus the sell gene, five possessed the sea gene (two with the seh gene and two with the tst gene) and four had the seb gene, one with the tst gene.

§This group comprised 13 chicken (all of agr type II), 1 sheep (agr type II), 3 goat (all of agr type I) and 8 bovine isolates ( 3 of $a g r$ type I and 5 of $a g r$ type II).

IIThis group comprised 2 sheep ( 1 each of agr types II and IV), 5 rabbit (all agr type IV) and 21 bovine isolates ( 1 of agr type 1, 13 of agr type II and 7 of agr type IV), including all 10 bovine isolates with an egc locus missing the seg gene, 3 of which were of agr type II and 7 of $a g r$ type IV.

possessing the pseudogenes $\psi$ ent 1 and $\psi e n t 2$, the selu gene or the seluv gene.

To date, the egc3 locus has only been reported in isolates from food (Letertre et al., 2003; Blaiotta et al., 2004), although genome sequencing has identified strain MRSA252 as being egc3 $3^{+}$(Holden et al., 2004). Chini et al. (2006) and Collery \& Smyth (2007) have demonstrated the usefulness of PCR-RFLP analysis with restriction endonucleases HindIII, $H p h \mathrm{I}$ and $B c c$ I for distinction of

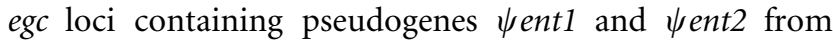
those harbouring either the selu or the seluv gene. The present investigation extended this PCR-RFLP analysis to allow distinction of egc loci harbouring the selu and selu genes using restriction enzymes BbvI and TseI. Alternatively, Blaiotta et al. $(2004,2006)$ demonstrated that PCR in conjunction with restriction endonuclease analysis of a $3375 \mathrm{bp}$ region encompassing $47 \mathrm{nt}$ upstream of the $3^{\prime}$ end of the selm gene to $610 \mathrm{nt}$ downstream of the $5^{\prime}$ end of the seg gene could be used to distinguish egc loci. However, the PCR-RFLP procedures developed by Collery \& Smyth (2007) and in this study have the advantage of specifically examining differences in the sei-seln intergenic region of interest.

\section{Clonality of $\mathbf{S}$. aureus isolates and egc locus types}

The distribution of $e g c$ locus types according to the agr genotypes of the 43 human and the 53 bovine, ovine, caprine, leporine and gallinaceous isolates are shown in Table 4. None of the animal isolates was of agr type III. All
14 agr type IV isolates, only one of which was of human origin, possessed an egc2 locus.

The human nasal isolates that possessed egcl loci were evenly distributed between agr types I, II and III. These strains were also evenly distributed between the previously described MLVA (sub)populations: four in cluster I, three in subcluster IIa, two in subcluster IIb, three in subcluster IIc and five subcluster IId, with the agr type III isolates being confined to MLVA subpopulations IIa and IIb (Collery et al., 2008). The distribution of the $e g c 3^{+}$isolates among the MLVA clusters and subclusters was: two in cluster I, ten in subcluster IIa, two in subcluster IIb, two in subcluster IIc and one in subcluster IId (Collery et al., 2008). Four of the ten isolates in MLVA subcluster IIa had been MLST typed (MC15 and MC26 as ST30, MC19 as ST484 and MC24 as ST938, all of which belong to CC30). The two egc2 ${ }^{+}$isolates belonged to MLVA cluster I (isolate MC40 - ST934, singleton, agr type I) and MLVA subcluster IIa (isolate MC25 - ST123, CC121, agr type IV). The latter isolate was tested for fusidic acid resistance using a $10 \mu \mathrm{g}$ disc in comparison with S. aureus strain Oxford. Both gave identical zones of growth inhibition, indicating that strain MC25 was fusidic acid sensitive. Thus, the latter isolate is a related clonal variant of the epidemic European fusidic acid-resistant impetigo strain (O'Neill et al., 2007; Larsen et al., 2008).

The egc type distributions of the animal isolates were evaluated on the basis of evidence of clonality from the present and previous studies (Table 5). The 13 gallinaceous isolates, which were all from broiler chickens in Northern Ireland (McCullagh et al., 1998), share several molecular 
Table 5. Clonality of bovine, leporine and gallinaceous S. aureus strains based on molecular typing characteristics and egc locus type

\begin{tabular}{|c|c|c|c|c|}
\hline Animal/country of origin & $n$ & Strain & Molecular typing characteristic ${ }^{\star}$ & egc locus type \\
\hline Chicken/Northern Ireland & 13 & DS55-DS67 & $\begin{array}{l}\text { RAPD type } 2 \text {, PFGE type I.24 and variants } \\
\text { I.24B-E, I.24G and I.24K†, agr type II }\end{array}$ & $e g c 1$ \\
\hline Rabbit/Belgium and Spain & 3 & DS31, DS46, DS53 & RAPD type 18 , agr type IV & $e g c 2$ \\
\hline Bovine/Ireland & 9 & $\begin{array}{l}\text { RF80, RF102, RF108, RF113, } \\
\text { RF122, RF110, RF114, } \\
\text { RF120, RF121 }\end{array}$ & $\begin{array}{l}\text { ET3 } \ddagger \text {, RAPD type } 7, h l g \text { RFLP type } 3 \text {, } \\
\text { ribotype } 4 \text {, agr type II }\end{array}$ & egc2 \\
\hline Bovine/USA & 3 & MSA930, MSA1005, MSA1047 & $\begin{array}{l}\text { ET1, RAPD type } 10, h l g \text { RFLP type } 5 \text {, } \\
\text { ribotype } 6 \text {, PFGE type H, agr type II }\end{array}$ & $\operatorname{egc} 2$ \\
\hline Bovine/USA & 7 & $\begin{array}{l}\text { PSA5, PSA6.1, MSA12.1, MSA26.1, } \\
\text { MSA31, MSA73.2, MSA148 }\end{array}$ & $\begin{array}{l}\text { ET36, RAPD type } 9 \text {, hlg RFLP type } 7 \text {, } \\
\text { ribotype } 1 \text {, agr type IV }\end{array}$ & $\operatorname{egc} 2$ \\
\hline Bovine/USA & 4 & $\begin{array}{l}\text { MSA10.6, MSA72.3, MSA103.14, } \\
\text { MSA1460 }\end{array}$ & $\begin{array}{l}\text { ET2, RAPD type } 2 \text {, hlg RFLP type } 4 \S \text {, } \\
\text { ribotype } 9 \$ \text {, agr type III }\end{array}$ & $e g c 1$ \\
\hline
\end{tabular}

${ }^{\star}$ MLEE typing (ET) data from Fitzgerald et al. (1997); RAPD typing data for bovine strains from Fitzgerald et al. (1997) and Smyth (2006); hlg RFLP typing data and ribotyping data from Fitzgerald et al. (2000); PFGE data from Fitzgerald (1997).

$\dagger$ PFGE data from McCullagh et al. (1998).

$¥$ Strain RF114 is ET40, a single enzyme MLEE variant of ET3 for shikimic acid dehydrogenase; strain RF80 was not typed by MLEE.

\$Strain MSA72.3 was not typed by hlg RFLP; strain MSA1460 is ribotype 2.

typing characteristics and possessed the pseudogenes $\psi$ ent 1 and $\psi$ ent 2 (Table 5). Seven of these isolates were of PFGE type I.24, which was the predominant PFGE type associated with skeletal infections (McCullagh et al., 1998). The other six strains had PFGE types with slightly different banding patterns from PFGE I.24, although related to it.

Three rabbit isolates, one from Spain and two from Belgium, were of the same randomly amplified polymorphic DNA (RAPD) type and agr type, and possessed an egc2 locus. Previous molecular typing characteristics were not available for the other two Belgian isolates. All of these isolates belonged to the so-called 'high virulence rabbit $S$. aureus clone' (Vancraeynest et al., 2006a, b).

Among the bovine isolates (Table 5), nine from Ireland were of multilocus enzyme electrophoresis (MLEE) type ET3 and RAPD type 7 (Selander et al., 1986; Kapur et al., 1995; Fitzgerald et al., 1997, 2000; Herron-Olson et al., 2007). All possessed an egc2 locus and were of agr type II. However, they could be subdivided into two groups based on the presence (six isolates: RF80, RF102, RF108, RF110, RF113 and RF122) or absence (three isolates: RF114, RF120 and RF121) of the SaPIbov pathogenicity island (i.e. the presence or absence of the sec, sell and tst genes), and belonged to the different but related PFGE types B1 and B2, respectively (Fitzgerald, 1997; Fitzgerald et al., 2001; Smyth et al., 2005).

Three bovine isolates of MLEE type ET1 and RAPD type 10, and seven strains of MLEE type ET36 and RAPD type 9 (Kapur et al., 1995; Fitzgerald et al., 1997, 2000), all from the USA, were of agr types II and IV, respectively. All possessed egc2 loci (Table 5). A further group of four isolates, all from the USA, of MLEE type ET2 and RAPD type 2 (Kapur et al., 1995; Fitzgerald et al., 1997, 2000) were of agr type II and had an egcl locus.

The remaining six bovine isolates had individual molecular typing characteristics. Four strains, three from the USA and one from Spain, had egc1 loci (MSA1363 - MLEE type ET7, RAPD type 4, agr type I; MSA1007 and DS37 - agr type II; and MSA915 - RAPD type 4, agr type I) (Selander et al., 1986; Kapur et al., 1995; Fitzgerald et al., 1997, 2000; Smyth, 2006). The other two isolates had egc2 loci - one strain from Argentina (DS42) was agr type I and the other from Denmark was agr type II.

The three Italian goat isolates were all of agr type I and had egc1 loci. Two of the three sheep isolates were of agr type II, one of Danish origin with an egcl locus, the other of Swedish origin with an $e g c 2$ locus, whilst the remaining Danish isolate was of agr type IV and had an egc2 locus that was missing the seg gene.

In a study of hospital- and community-acquired meticillinresistant $S$. aureus, the egc locus was found to be restricted to isolates of clonal complex CC5 (ST5:USA100) and CC30 (ST30:USA1100 and ST36:USA200) genomic backgrounds (Diep et al., 2006). However, using microarray genotyping with $S$. aureus representative of all major clonal complexes, Monecke et al. (2008) found the egc locus additionally in CC10, CC20 and CC25, and in MLST types ST22, ST39, ST45, ST151, ST228 and ST254. The human nasal isolates examined by Collery et al. (2008) and included in the present study that were MLST typed as CC30 (ST30 and ST938) were $\operatorname{selu}_{\mathrm{v}}{ }^{+}$, and the one strain that was MLST

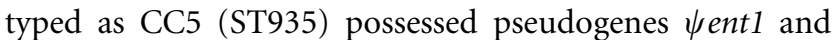
went2 in its egc locus. Holtfreter et al. (2007) found that 
$87.9 \%$ of 33 nasal isolates of CC30 possessed a selm vene $_{\mathrm{v}}$ and a 'selu' gene. On the basis of the present and the aforementioned findings, and the data from genomesequenced isolates Mu50, N315 and MRSA252, the evidence substantiates that the egcl locus occurs in CC5 and the egc3 locus in CC30. However, isolates belonging to other ST types (ST6, ST109, ST932, ST934, ST937 and ST singletons) and clonal complexes (CC6, CC9, CC10, CC20, CC22, CC25 and CC45) have also been shown to possess the egc1 or egc3 locus (Holtfreter et al., 2007; Collery et al., 2008).

\section{Screening of $S$. aureus from infections in companion animals, pigs and horses for egc loci}

Of the 45 isolates from cats, dogs, rats, pigs and horses screened by the procedure of Letertre et al. (2003) for egc loci, 33 were $\mathrm{egc}^{-}$. The isolates that yielded PSE1/PSE4 amplimers were examined by PCR-RFLP to confirm their pseudogene $\psi e n t 1$ and $\psi e n t 2$ status, and their selu and seluv status. Of the six canine isolates, two had egc loci, one with pseudogenes $\psi$ ent 1 and $\psi e n t 2$, and one with the selu gene. Three of the four porcine isolates possessed pseudogenes $\psi e n t 1$ and $\psi e n t 2$, whilst the remaining isolate was $\operatorname{selu}_{\mathrm{v}}{ }^{+}$. A total of 6 of the 28 equine isolates, all nasal in origin, had the selu gene. None of the four feline or three rodent isolates had an egc locus.

Few data are available on the prevalence of enterotoxin or enterotoxin-like genes in S. aureus isolates from cats, dogs, rats, pigs and horses. Nitzsche et al. (2007) reported the seg or sei gene or both in $38.7 \%$ of $142 \mathrm{~S}$. aureus isolates from pig carcasses sampled at abattoirs. In a study of $S$. aureus isolates from 20 pork meat samples and 36 pig carcasses, Hwang et al. (2007) detected egc genes in 22 strains $(39.3 \%), 27.3 \%$ of which had a 'selu' gene.

\section{Conclusions}

The present findings demonstrate that $S$. aureus isolates can be screened directly using the PCR primers of Letertre et al. (2003) and PCR-RFLP to detect the presence of and to characterize the egc loci, although some human nasal isolates were refractory to these procedures. The PCR primers for the 'hypervariable' region designed in the present study with subsequent sequencing of amplimers would offer a useful alternative or adjunct procedure for distinguishing selu and selu $\mathrm{v}_{\mathrm{v}}$ genes or the pseudogenes

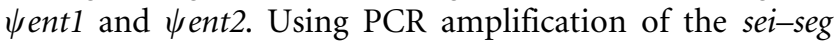
region, Jarraud et al. (2001) showed that the egc locus was highly prevalent in isolates from toxic shock syndrome (59\% of 63 isolates), staphylococcal scalded skin syndrome ( $92 \%$ of 39 isolates), suppurative infections (67\% of 58 isolates) and nasal carriage ( $57 \%$ of 70 isolates). Jarraud et al. (2002) also found a strong association between the presence of the egc locus and amplified fragment length polymorphism group AF1, which was highly represented by isolates of agr type IV from bullous impetigo and scalded skin syndrome. Whilst it remains to be established whether or not there is a correlation between such infections and the type of egc locus present, it is noteworthy that all of the agr type IV isolates examined herein possessed a selu gene. Further detailed study of egc polymorphisms in $S$. aureus may provide phylogenetic associations with other actual or potential infection markers (Peacock et al., 2002).

\section{ACKNOWLEDGEMENTS}

M.M.C. was in receipt of a studentship from the Sarah Purser Medical Research Fund and of a Trinity College postgraduate research studentship. D. S. S. was in receipt of a Teagasc Walsh Fellowship. The authors acknowledge the generosity of Damien Y. Thomas in providing the unpublished egc locus sequence of strain A900624. The authors thank Nola Leonard, Robert Foschino, José Penadés, John Rodgers, Tore Tollersrud, Dieter Vancraeynest and Petra Winter who donated animal-associated strains, and Timothy Foster, Angela Rossney, Giuseppe Blaiotta and Sophie Jarraud who provided control strains used in this study.

\section{REFERENCES}

Ayyadevara, S., Thaden, J. J. \& Shmookler Reis, R. J. (2000). Discrimination of primer $3^{\prime}$-nucleotide mismatch by Taq DNA polymerase during polymerase chain reaction. Anal Biochem 284, 1118.

Bania, J., Dabrowska, A., Korzekwa, K., Zarczynska, A., Bystron, J., Chrzanowska, J. \& Molenda, J. (2006a). The profiles of enterotoxin genes in Staphylococcus aureus from nasal carriers. Lett Appl Microbiol 42, 315-320.

Bania, J., Dabrowska, A., Bystron, J., Korzekwa, K., Chrzanowska, J. \& Molenda, J. (2006b). Distribution of newly described enterotoxinlike genes in Staphylococcus aureus from food. Int J Food Microbiol 108, 36-41.

Becker, K., Friedrich, A. W., Peters, G. \& von Eiff, C. (2004). Systematic survey on the prevalence of genes coding for staphylococcal enterotoxins SEIM, SElO, and SElN. Mol Nutr Food Res 48, 488-495.

Blaiotta, G., Ercolini, D., Pennacchia, C., Fusco, V., Casaburi, A., Pepe, O. \& Villani, F. (2004). PCR detection of staphylococcal enterotoxin genes in Staphylococcus spp. strains isolated from meat and dairy products. Evidence for new variants of $s e G$ and seI in $S$. aureus AB-8802. J Appl Microbiol 97, 719-730.

Blaiotta, G., Fusco, V., von Eiff, C., Villani, F. \& Becker, K. (2006). Biotyping of Staphylococcus aureus by enterotoxin gene cluster $(e g c)$ polymorphism and spa typing analysis. Appl Environ Microbiol 72, 6117-6123.

Boerema, J. A., Clemens, R. \& Brightwell, G. (2006). Evaluation of molecular methods to determine enterotoxigenic status and molecular genotype of bovine, ovine, human and food isolates of Staphylococcus aureus. Int J Food Microbiol 107, 192-201.

Chen, T.-R., Chiou, C.-S. \& Tsen, H.-Y. (2004). Use of novel PCR primers specific to the genes of staphylococcal enterotoxin $G, H$, I for the survey of Staphylococcus aureus strains isolated from foodpoisoning cases and food samples in Taiwan. Int J Food Microbiol 92, 189-197.

Chiang, Y.-C., Liao, W.-W., Fan, C.-M., Pai, W.-Y., Chiou, C.-H. \& Tsen, H.-Y. (2008). PCR detection of staphylococcal enterotoxins (SEs) N, 
$\mathrm{O}, \mathrm{P}, \mathrm{Q}, \mathrm{R}, \mathrm{U}$, and survey of SE types in Staphylococcus aureus isolates from food-poisoning cases in Taiwan. Int J Food Microbiol 121, 66-73.

Chini, V., Dimitracopoulos, G. \& Spiliopoulou, I. (2006). Occurrence of enterotoxin gene cluster and the toxic shock syndrome toxin 1 among clinical isolates of methicillin-resistant Staphylococcus aureus is related to clonal type and agr group. J Clin Microbiol 44, 1881-1883.

Collery, M. M. \& Smyth, C. J. (2007). Rapid differentiation of Staphylococcus aureus isolates harbouring egc loci with pseudogenes $\psi e n t 1$ and $\psi e n t 2$ and the selu or selu $u_{\mathrm{v}}$ gene using PCR-RFLP. J Med Microbiol 56, 208-216.

Collery, M. M., Smyth, D. S., Twohig, J. M., Shore, A. C., Coleman, D. C. \& Smyth, C. J. (2008). Molecular typing of nasal carriage isolates of Staphylococcus aureus from an Irish university student population based on toxin gene PCR, agr locus types and multiple locus, variable number tandem repeat analysis. J Med Microbiol 57, 348-358.

Diep, B. A., Carleton, H. A., Chang, R. F., Sensabaugh, G. F. \& Perdreau-Remington, F. (2006). Roles of 34 virulence genes in the evolution of hospital- and community-associated strains of methicillin-resistant Staphylococcus aureus. J Infect Dis 193, 1495-1503.

Fitzgerald, J. R. (1997). Population analysis of Staphylococcus aureus from bovine mastitis. $\mathrm{PhD}$ thesis, University of Dublin.

Fitzgerald, J. R., Meaney, W. J., Hartigan, P. J., Smyth, C. J. \& Kapur, V. (1997). Fine-structure molecular epidemiological analysis of Staphylococcus aureus recovered from cows. Epidemiol Infect 119, 261269.

Fitzgerald, J. R., Hartigan, P. J., Meaney, W. J. \& Smyth, C. J. (2000). Molecular population and virulence factor analysis of Staphylococcus aureus from bovine intramammary infection. J Appl Microbiol 88, $1028-1037$.

Fitzgerald, J. R., Monday, S. R., Foster, T. J., Bohach, G. A., Hartigan, P. J., Meaney, W. J. \& Smyth, C. J. (2001). Characterization of a putative pathogenicity island from bovine Staphylococcus aureus encoding multiple superantigens. J Bacteriol 183, 63-70.

Gilot, P., Lina, G., Cochard, T. \& Poutrel, B. (2002). Analysis of the genetic variability of genes encoding the RNA III-activating components Agr and TRAP in a population of Staphylococcus aureus strains isolated from cows with mastitis. J Clin Microbiol 40, 40604067.

Herron-Olson, L., Fitzgerald, J. R., Musser, J. M. \& Kapur, V. (2007). Molecular correlates of host specialization in Staphylococcus aureus. PLoS One 2, e1120.

Holden, M. T. G., Feil, E. J., Lindsay, J. A., Peacock, S. J., Day, N. P. J., Enright, M. C., Foster, T. J., Moore, C. E., Hurst, L. \& other authors (2004). Complete genomes of two clinical Staphylococcus aureus strains: evidence for the rapid evolution of virulence and drug resistance. Proc Natl Acad Sci U S A 101, 9786-9791.

Holtfreter, S., Grumann, D., Schmudde, M., Nguyen, H. T. T., Eichler, P., Strommenger, B., Kopron, K., Kolata, J., Giedrys-Kalemba, S. \& other authors (2007). Clonal distribution of superantigen genes in clinical Staphylococcus isolates. J Clin Microbiol 45, 2669-2680.

Hwang, S. Y., Kim, S. H., Jang, E. J., Kwon, N. H., Park, Y. K., Koo, H. C., Jung, W. K., Kim, J. M. \& Park, Y. H. (2007). Novel multiplex PCR for the detection of the Staphyloccus aureus superantigen and its application to raw meat isolates in Korea. Int J Food Microbiol 117, 99-105.

landolo, J. J., Worrell, V., Groicher, K. H., Qian, Y., Tian, R., Kenton, S., Dorman, A., Ji, H., Loh, P. \& other authors (2002). Comparative analysis of the genomes of the temperate bacteriophages $\phi 11, \phi 12$ and $\phi 13$ of Staphylococcus aureus 8325. Gene 289, 109-118.

Jarraud, S., Peyrat, M. A., Lim, A., Tristan, A., Bes, M., Mougel, C., Etienne, J., Vandenesch, F., Bonneville, M. \& Lina, G. (2001). egc, a highly prevalent operon of enterotoxin gene, forms a putative nursery of superantigens in Staphylococcus aureus. J Immunol 166, 669-677.

Jarraud, S., Mougel, C., Thioulouse, J., Lina, G., Meugnier, H., Forey, F., Nesme, X., Etienne, J. \& Vandenesch, F. (2002). Relationships between Staphylococcus aureus genetic background, virulence factors, agr groups (alleles), and human disease. Infect Immun 70, 631-641.

Kapur, V., Sischo, W. M., Greer, R. S., Whittam, T. S. \& Musser, J. M. (1995). Molecular population genetic analysis of Staphylococcus aureus recovered from cows. J Clin Microbiol 33, 376-380.

Kuhn, G., Francioli, P. \& Blanc, C. S. (2006). Evidence for clonal evolution among highly polymorphic genes in methicillin-resistant Staphylococcus aureus. J Bacteriol 188, 169-178.

Kuroda, M., Ohta, T., Uchiyama, I., Baba, T., Yuzawa, H., Kobayashi, I., Cu, L., Oguchi, A., Aoki, K.-I. \& other authors (2001). Whole genome sequencing of meticillin-resistant Staphylococcus aureus. Lancet 357, 1225-1240.

Larsen, A. R., Skov, R. L., Jarlier, V. \& Henriksen, A. S. (2008). Epidemiological differences between the UK and Ireland versus France in Staphylococcus aureus isolates resistant to fusidic acid from community-acquired skin and soft tissue infections. J Antimicrob Chemother 61, 589-594.

Letertre, C., Perelle, S., Dilasser, F. \& Fach, P. (2003). Identification of a new putative enterotoxin SEU encoded by the egc cluster of Staphylococcus aureus. J Appl Microbiol 95, 38-43.

Lina, G., Bohach, G. A., Nair, S. P., Hiramatsu, K., Jouvin-Marche, E. \& Mariuzza, R. (2004). Standard nomenclature for the superantigens expressed by Staphylococcus. J Infect Dis 189, 2334-2336.

McCullagh, J. J., McNamee, P. T., Smyth, J. A. \& Ball, H. J. (1998). The use of pulsed field gel electrophoresis to investigate the epidemiology of Staphylococcus aureus infection in commercial broiler flocks. Vet Microbiol 63, 275-281.

Monday, S. R. \& Bohach, G. A. (1999). Use of multiplex PCR to detect classical and newly described pyrogenic exotoxin genes in staphylococcal isolates. J Clin Microbiol 37, 3411-3414.

Monday, S. R. \& Bohach, G. A. (2001). Genes encoding staphylococcal enterotoxins $G$ and I are linked and separated by DNA related to other staphylococcal enterotoxins. J Nat Toxins 10, 1-8.

Monecke, S., Slickers, P. \& Ehricht, R. (2008). Assignment of Staphylococcus aureus isolates to clonal complexes based on microarray analysis and pattern recognition. FEMS Immunol Med Microbiol 53, 237-251.

Munson, S. H., Tremaine, M. T., Betley, M. J. \& Welch, R. A. (1998). Identification and characterization of enterotoxins $G$ and I from Staphylococcus aureus. Infect Immun 66, 3337-3348.

Nashev, D., Toshkova, K., Bizeva, L., Akideden, Ö., Lämmler, C. \& Zschöck, M. (2007). Distribution of enterotoxin genes among carriage- and infection-associated isolates of Staphylococcus aureus. Lett Appl Microbiol 45, 681-685.

Nitzsche, S., Sweifel, C. \& Stephan, R. (2007). Phenotypic and genotypic traits of Staphylococcus aureus strains from pig carcasses. Vet Microbiol 120, 292-299.

Novick, R. (1967). Properties of cryptic high-frequency transducing phages in Staphylococcus aureus. Virology 33, 155-166.

Omoe, K., Hu, D.-L., Takahashi-Omoe, H., Nakane, A. \& Shinagawa, K. (2005). Comprehensive analysis of classical and newly described staphylococcal superantigenic toxin genes in Staphylococcus aureus isolates. FEMS Microbiol Lett 246, 191-198.

O'Neill, A. J., Larsen, A. R., Henriksen, A. S. \& Chopra, I. (2007). Characterization of the epidemic European fusidic acid-resistant impetigo clone of Staphylococcus aureus. J Clin Microbiol 45, 15051510. 
Peacock, S. J., Moore, C. E., Justice, A., Kantzanou, M., Story, L., Mackie, K., O'Neill, G. \& Day, N. P. J. (2002). Virulent combinations of adhesion and toxin genes in natural populations of Staphylococcus aureus. Infect Immun 70, 4987-4996.

Selander, R. K., Caugant, D. A., Ochman, H., Musser, J. M., Gilmour, M. N. \& Whittam, T. S. (1986). Methods of multilocus enzyme electrophoresis for bacterial population genetics and systematics. Appl Environ Microbiol 51, 873-884.

Simsek, M. \& Adnan, H. (2000). Effect of single mismatches at $3^{\prime}$-end of primers on polymerase chain reaction. Med Sci 2, 11-14.

Smyth, D. S. (2006). Molecular genetic typing of Staphylococcus aureus from cows, goats, sheep, rabbits and chickens. $\mathrm{PhD}$ thesis, University of Dublin.

Smyth, D. S., Hartigan, P. J., Meaney, W. J., Fitzgerald, J. R., Deobald, C. F., Bohach, G. A. \& Smyth, C. J. (2005). Superantigen genes encoded by the egc cluster and SaPlbov are predominant among Staphylococcus aureus isolates from cows, goats, sheep, rabbits and poultry. J Med Microbiol 54, 401-411.
Thomas, D. Y., Jarraud, S., Lemercier, B., Cozon, G., Echasserieau, K., Etienne, J., Gougeon, M.-L., Lina, G. \& Vandenesch, F. (2006). Staphylococcal enterotoxin-like toxins U2 and V, two new staphylococcal superantigens arising from recombination within the enterotoxin gene cluster. Infect Immun 74, 4724-4734.

Vancraeynest, D., Hermans, K. \& Haesebrouck, F. (2006a). Prevalence of genes encoding exfoliative toxins, leucotoxins and superantigens among high and low virulence rabbit Staphylococcus aureus strains. Vet Microbiol 117, 211-218.

Vancraeynest, D., Haesebrouck, F., Deplano, A., Denis, O., Godard, C., Wildemauwe, C. \& Hermans, K. (2006b). International dissemination of a high virulence rabbit Staphylococcus aureus clone. J Vet Med B Infect Dis Vet Public Health 53, 418-422.

van Wamel, W. J. B., Rooijakkers, S. H. M., Ruyken, M., van Kessel, K. P. M. \& van Strijp, J. A. G. (2006). The innate immune modulators staphylococcal complement inhibitor and chemotaxis inhibitory protein of Staphylococcus aureus are located on $\beta$-hemolysinconverting bacteriophages. J Bacteriol 188, 1310-1315. 